\title{
EFFECTS OF ORTHOPEDIC SKELETAL CLASS III CORRECTION IN GROWING SUBJECTS USING SKELETAL ANCHORAGE AND CLASS III ELASTICS
}

\author{
Dina Osman ElAbbasy*
}

\begin{abstract}
Aim of the study: The objective of this study was to evaluate the skeletal and dental effects of intermaxillary Class III elastics using bone anchored miniplates compared to an untreated Class III control group.
\end{abstract}

Subjects and methods: 24 subjects (14 females and 10 males) having skeletal Class III malocclusion with maxillary deficiency with an age range of 8-11 years old were divided into two groups 12 patients each $(n=12)$. Group A constituted treatment with Class III elastics anchored to 4 titanium miniplates, 2 anchored in the zygomatic buttress of the maxilla and 2 miniplates anchored in the symphyseal region of the mandible at the lateral/canine region. Group B $(n=12)$ constituted untreated skeletal Class III cases (control group). The treatment and observation periods for both groups were 8 months. Lateral cephalometric radiographs were taken for the patients at start of treatment (T1) and at the end of the treatment/observation periods (T2). The radiographs were analyzed by performing lateral cephalometric analysis. Independent student $t$ test was done to compare variables between the two groups.

Results: There was correction of the skeletal Class III in the miniplates group with statistically significant increase in angle SNA (mean $3.50^{\circ} \pm 0.68$ ), A-Nperp (mean 4.04mm \pm 1.20 ), ANB (mean $4.06^{\circ} \pm 0.95$ ) and Witts appraisal (mean $4.91 \mathrm{~mm} \pm 1.76$ ) .Slight mandibular retrusion occurred with a reduction in angle SNB (mean $-0.56^{\circ} \pm 0.57$ ). Changes in B-Nperp were $(-1.85 \mathrm{~mm} \pm 1.36$ ). Overjet correction was obtained and no significant changes in the maxillary incisor angulation was observed. There was proclination of mandibular incisors by (mean $6.43^{\circ} \pm 2.11$ ).

Conclusions: The use of intermaxillary Class III elastics and miniplates in the orthopedic treatment of skeletal Class III is a successful technique with more skeletal than dental effects.

\footnotetext{
* Lecturer Department of Orthodontics, Cairo University
} 


\section{INTRODUCTION}

Skeletal Class III malocclusion is one of the most challenging problems to treat. The etiology is maxillary retrognathism, mandibular prognathism or a combination of both. Dentoalveolar compensation is sometimes evident in the form of proclined maxillary incisors and/or retroclined mandibular incisors (Ellis \& McNamara, 1984 and Guyer et al, 1986).

The most common treatment modality employed for correction of skeletal class III in growing patients is the facemask or reverse-pull headgear (RPHG). Its main purpose of action is maxillary protraction and limitation of excessive mandibular growth. Treatment effects include forward movement and anticlockwise rotation of the maxilla as well as clockwise rotation of the mandible which increases the lower anterior facial height. Moreover there is proclination of upper incisors, retroclination of lower incisors and mesialization/extrusion of the maxillary molars (Williams et al, 1997; Kapust et al, 1998; Baccetti et al, 1998 and Turley, 2002). It is normally attached with hooks to an intraoral fixed appliance that is bonded to teeth. Dentoalveolar side effects include further proclination of upper incisors and retroclination of mandibular incisors (Chong et al, 1996 and Kim et al, 1999). To overcome these unwanted dental side effects and amplify the skeletal effects, it has always been the focus of orthodontists to find alternative treatment modalities. Hence the idea of skeletal anchorage emerged. It is a new technique that is being widely applied in the field of orthodontics and dentofacial orthopedics. Vincent kokich was a pioneer in this field when he introduced ankylosed canines as means of anchorage for protraction of the maxilla (Kokich et al, 1985).

The use of titanium miniplates has gained wide popularity in recent years. Initially used for maxillofacial procedures and fixation of fractures, it has recently found its way in orthodontics. Its use is believed to limit the dental effects and maximize the skeletal orthopedic effects (Singer et al, 2000; Enacar et al, 2005 and Kircelli \& Pektas, 2006)
Facemasks anchored to maxillary miniplates permit the vector of the protraction force to pass through the center of resistance of the maxilla, hence achieving pure maxillary advancement with minimal rotation. (Chung et al, 2002; Kircelli et al, 2006; Cornelis et al., 2007 and Kaya et al, 2011;) Some authors compared between the bone-anchored facemask and facemask with rapid maxillary expansion (RME) and reported greater amounts of maxillary protraction compared to facemask and RME (Cevidanes et al, 2010).

Another treatment modality was introduced by (De Clerck et al, 2009) and has gained popularity in the treatment of skeletal Class III malocclusion in the late mixed or early permanent dentition is bone anchored intermaxillary elastics and has offered the opportunity of gaining more orthopaedic changes and clinical progress in the sagittal jaw relationship while keeping dentoalveolar side effects at a minimum (Cevidanes et al, 2010; De Clerck et al, 2010; Heymann et al, 2010; Nguyen et al, 2011 and Coscia et al, 2012).

The aim of this study was to evaluate the skeletal and dental effects of Class III elastics attached to bone anchored miniplates in the treatment of skeletal Class III malocclusion with maxillary deficiency in comparison with a group of untreated controls.

\section{MATERIALS AND METHODS}

A total of 24 growing patients with a mean age of 10.2 years, 14 females and 10 males, suffering from skeletal Class III malocclusion were selected from private practice in Cairo, Egypt. Mean treatment and observational period were 8 months.

The criteria for selection were as follows (Figure 1)

- Age range 9-12 years old (prepubertal stage of growth confirmed by cervical vertebral maturation method (CS1-CS3) (Baccetti et al, 2005)

- Skeletal Class III with maxillary deficiency and normal mandibular growth $\left(\mathrm{ANB},<0^{\circ}\right.$ and Witts appraisal $<-1 \mathrm{~mm}$ ) 
- True skeletal Class III without any anterior functional shifts

- Normal or slightly reduced mandibular plane angle

- Anterior crossbite or edge to edge relationship

- Class III molar relationship

- No previous orthodontic or orthopedic treatment

- No previous extractions

- Absence of syndromes and anomalies

Patients and their parents were informed about the sequence of treatment and consent forms were signed.

Patients were divided into 2 groups each constituting 12 patients : Group A (treatment group , $\mathrm{n}=12,7$ females, 5 males) and Group B (control group, $\mathrm{n}=12,5$ females and 7 males).

In Group A, each patient received 4 titanium miniplates placed bilaterally ( (Surgi-Tec, Bruges, Belgium), two placed in the infrazygomatic crest of the maxilla and two were placed in the mandibular symphysis inferior to the right and left permanent lateral incisors and canines. Attention was given to avoid trauma to any permanent teeth roots. The surgical procedure was standard for all the patients where mucoperiosteal flaps were elevated under local anesthesia and miniplates were bent to adapt on the bone surface and achieve ideal position for the attachment portion. The miniplates were fixed with self-tapping titanium bone screws $(2.0 \mathrm{~mm}$ in diameter and $6.0 \mathrm{~mm}$ in length).The attachment portion had a tube shaped extension which was suitable for the retention of the intermaxillary elastics and resist dislodgement. It was carefully exposed over the keratinized gingiva (Figure 2). All mucoperiosteal flaps were sutured with 3.0 polyglactin 910 .

Two weeks were allowed for tissues to heal after which intermaxillary elastics were applied bilaterally from the maxillary to the mandibular miniplates at a force of 200 grams per side exerted by the elastics (1/4", 6oz).. Instructions were given for the elastics to be worn 24 hrs /day even during eating while maintaining strict intraoral hygiene measures. Instructions were given for the elastics to be changed one time per day.

Elastics were discontinued when the overjet has been corrected to $4 \mathrm{~mm}$.

The control group patients received no treatment but only observation for an average of 8 months and were matched to those in the treatment groups.

Digitized lateral cephalograms were taken for all patients in the two study groups at T1 and T2 and were then imported into Dolphin software (version 11.7;Dolphin Imaging and Management Solutions, Chatsworth, Calif) by a single investigator to trace and evaluate skeletal and dental changes. The following angular and linear measurements were done:

SNA: Angle formed by Sella, Nasion and A point. Indicates sagittal position of the maxilla relative to the anterior cranial base

SNB: Angle formed by Sella, Nasion and B point. Indicates sagittal position of the mandible relative to the anterior cranial base

ANB: Angle formed by A point, Nasion and B point. Indicates the relative position of the maxilla to mandible

Witts appraisal: The linear distance between the perpendicular projections of points A \& B onto the functional occlusal plane

A-Nperp: The linear distance between point A and a vertical line passing through Nasion perpendicular to Frankfort Horizontal

Pog-Nperp: The linear distance between Pogonion and avertical line passing through Nasion perpendicular to Frankfort Horizontal

SN/GoGn: Mandibular plane inclination with the $\mathrm{SN}$ plane 
U1/SN: Inclination of the maxillary incisors relative to the $\mathrm{SN}$ plane

L1/MP: Inclination of the mandibular incisors relative to the mandibular plane
To evaluate the measurements reliability, the same investigator repeated the measurements 3 weeks later for 10 randomly selected patients and intraclass correlation coefficients were calculated.

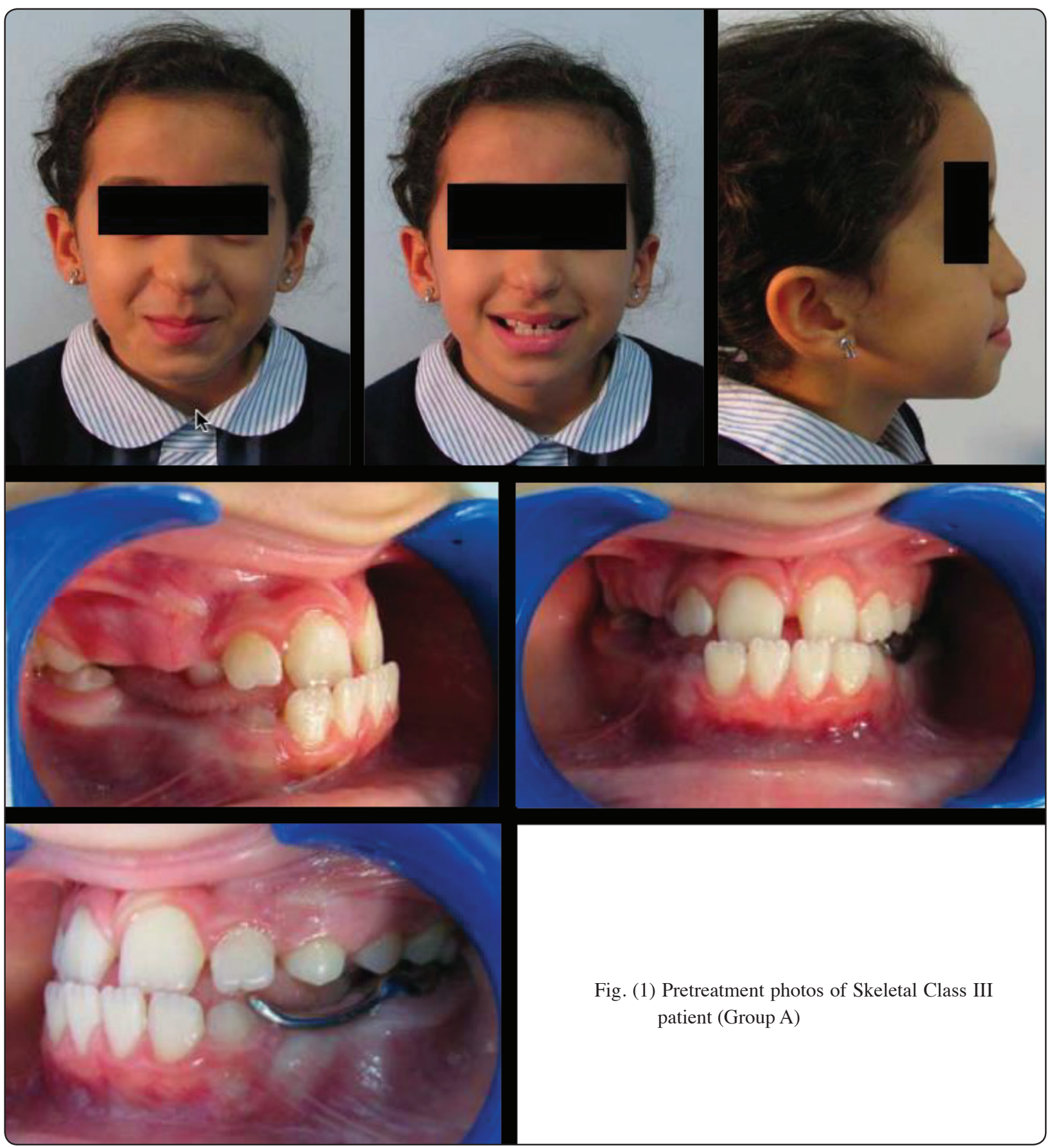




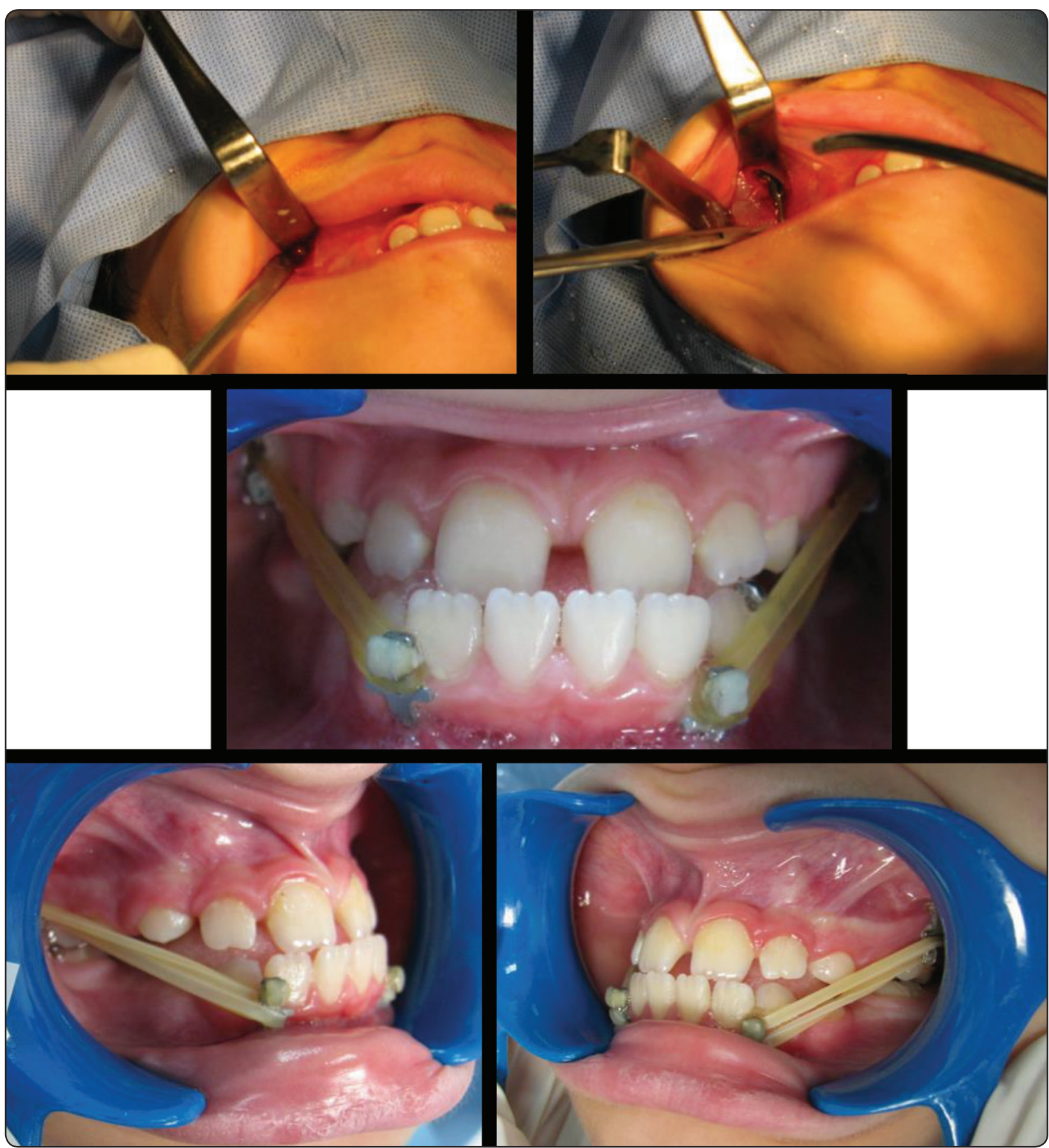

Fig. (2) Surgical procedure and miniplate placement in treatment group patient followed by application of the intermaxillary elastics (Group A)

\section{Statistical Methods}

All Data were collected, tabulated and subjected to statistical analysis. Statistical analysis was performed by SPSS in general (version 17), while Microsoft office Excel was used for data handling and graphical presentation.

Quantitative variables were described by the Mean, Standard Deviation (SD), the Range (Minimum - Maximum) ,Standard Error (SE) and 95\% confidence interval of the mean. 
Qualitative categorical variables were described by proportions and Percentages.

Shapiro-Wilk test of normality was used to test normality hypothesis of all quantitative variables for further choice of appropriate parametric and non parametric tests. Mostly the variables were found normally distributed allowing the use of parametric tests. Paired samples $\mathbf{t}$ test was used for comparing the Post and Pre within each group. Independent samples $\mathbf{t}$ test was used for comparing the difference (Post-Pre) between the two groups. Chi-squared test was applied for 2 by 2 contingency table.

Significance level was considered at $\mathbf{P}<\mathbf{0 . 0 5}$ (S); while for $\mathbf{P}<\mathbf{0 . 0 1}$ was considered highly significant (HS). Two Tailed tests were assumed throughout the analysis for all statistical tests.

\section{RESULTS}

The treatment duration as well as the observation period were 8 months for Groups $\mathrm{A}$ and $\mathrm{B}$ respectively.

Regarding gender and age distribution, no statistically significant differences were present between groups A and B (Table 1, 2).

The cephalometric values for the two study groups at T1 (Table 3) show no statistically significant differences which reveals that the two groups were properly matched with regards to skeletal and dental malocclusion.
The changes that occurred from $\mathrm{T} 1$ to $\mathrm{T} 2$ revealed significant influences from active treatment (Table 4). Angle SNA and the linear measurement A-Nperp showed significant improvements in Group A compared to Group B with a mean increase value of $3.50^{\circ}$ and $4.04 \mathrm{~mm}$ respectively. ANB angle and Witts appraisal also showed marked increase of a mean value of $4.06^{\circ}$ and $4.91 \mathrm{~mm}$ in Group A. Statistically significant restraint on forward mandibular growth was achieved in the treatment group compared to controls where angle SNB and the linear measurement Pog-Nperp decreased by $0.24^{\circ}$ and $1.85 \mathrm{~mm}$ respectively, denoting improvement of sagittal skeletal relationship. Regarding mandibular plane inclination, no significant changes were noted between the 2 groups. Dental changes were not evident for maxillary incisor inclination between the two study groups whereas significant proclination occurred for mandibular incisors with a mean value of $6.43^{\circ}$

With regards to treatment changes, there was a significant improvement in overjet and overbite as well as soft tissue features and profile concavity in the treatment group (Figure 3). This was a result of the forward displacement of the maxilla by Class III elastics protraction effect. This helped to protract the midface forward and improve the facial profile of the patients while maintaining the position of the mandible impeding further protrusion. Cephalometric tracing for Group A at T2 is shown in (Figure 4)

TABLE (1) Gender distribution in the study sample

\begin{tabular}{|c|c|c|c|c|c|c|c|}
\hline & \multicolumn{2}{|c|}{ Males } & \multicolumn{2}{c|}{ Females } & \multirow{2}{*}{ Total } & Chi-squared & \multirow{2}{*}{ P value } \\
\cline { 2 - 6 } & Frequency & Percent & Frequency & Percent & & \\
\hline Control & 7 & $58.3 \%$ & 5 & $41.7 \%$ & 12 & \multirow{2}{*}{0.67} & 0.41422 \\
\hline Miniplates \& elastics & 5 & $41.7 \%$ & 7 & $58.3 \%$ & 12 & & \\
\hline Total & 12 & $50.0 \%$ & 12 & $50.0 \%$ & 24 & & \\
\hline
\end{tabular}


TABLE (2) Independent Samples t-test for comparing mean age of the two groups

\begin{tabular}{|c|c|c|c|c|c|c|c|c|c|c|c|c|}
\hline & \multicolumn{6}{|c|}{ Differences } & \multicolumn{2}{|c|}{$\begin{array}{l}95 \% \text { Confidence } \\
\text { Interval of the } \\
\text { Difference }\end{array}$} & \multirow[t]{2}{*}{$\mathrm{t}$} & \multirow[t]{2}{*}{$\mathrm{df}$} & \multirow[t]{2}{*}{ P-value } \\
\hline & & $\mathrm{N}$ & Mean & $\mathrm{SD}$ & SEM & Mean & SD & Lower & Upper & & & \\
\hline \multirow{2}{*}{ Age } & Control & 12 & 10.03 & 1.46 & 0.42 & \multirow{2}{*}{0.29} & \multirow{2}{*}{0.55} & \multirow{2}{*}{-0.85} & \multirow{2}{*}{1.43} & \multirow{2}{*}{0.53} & \multirow{2}{*}{22} & \multirow{2}{*}{0.60142} \\
\hline & $\begin{array}{l}\text { Miniplates } \\
\text { and elastics }\end{array}$ & 12 & 9.74 & 1.23 & 0.36 & & & & & & & \\
\hline
\end{tabular}

\section{$P>0.05$ Non Significant}

TABLE (3) Cephalometric measurements of the control and treatment group at T1

\begin{tabular}{|c|c|c|c|c|c|c|c|c|c|}
\hline & \multicolumn{5}{|c|}{ Differences } & \multicolumn{2}{|c|}{$\begin{array}{c}95 \% \text { Confidence Interval } \\
\text { of the Difference }\end{array}$} & \multirow{2}{*}{$\mathrm{P}$ value } \\
\hline & & $\mathrm{N}$ & Mean & SD & Mean & SD & Lower & Upper & \\
\hline \multirow{2}{*}{ SNA $^{\circ}$} & Control & 12 & 78.76 & 2.27 & \multirow{2}{*}{2.72} & \multirow{2}{*}{0.56} & \multirow{2}{*}{-1.78} & \multirow{2}{*}{0.55} & \multirow{2}{*}{0.28771} \\
\hline & miniplates and elastics & 12 & 76.04 & 2.48 & & & & & \\
\hline \multirow{2}{*}{$\mathrm{SNB}^{\circ}$} & Control & 12 & 82.13 & 3.82 & \multirow{2}{*}{1.67} & \multirow{2}{*}{0.39} & \multirow{2}{*}{-0.54} & \multirow{2}{*}{1.06} & \multirow{2}{*}{0.51006} \\
\hline & miniplates and elastics & 12 & 80.46 & 3.06 & & & & & \\
\hline \multirow{2}{*}{$\mathrm{ANB}^{\circ}$} & Control & 12 & -3.37 & 1.38 & \multirow{2}{*}{-1.05} & \multirow{2}{*}{0.56} & \multirow{2}{*}{-2.00} & \multirow{2}{*}{0.33} & \multirow{2}{*}{0.15234} \\
\hline & miniplates and elastics & 12 & -4.42 & 1.37 & & & & & \\
\hline \multirow{2}{*}{$\begin{array}{c}\text { A-Na } \\
\text { Perp }(\mathrm{mm})\end{array}$} & Control & 12 & -2.53 & 2.30 & \multirow{2}{*}{1.12} & \multirow{2}{*}{0.55} & \multirow{2}{*}{-1.23} & \multirow{2}{*}{1.04} & \multirow{2}{*}{0.27621} \\
\hline & miniplates and elastics & 12 & -3.65 & 2.15 & & & & & \\
\hline \multirow{2}{*}{$\begin{array}{c}\text { Pog-Na } \\
\text { Perp }(m m)\end{array}$} & Control & 12 & 1.32 & 3.14 & \multirow{2}{*}{-0.82} & \multirow{2}{*}{1.12} & \multirow{2}{*}{-0.68} & \multirow{2}{*}{0.35} & \multirow{2}{*}{0.5981} \\
\hline & miniplates and elastics & 12 & 2.14 & 2.46 & & & & & \\
\hline \multirow{2}{*}{ Witts(mm) } & Control & 12 & -5.53 & 2.43 & & & & & \\
\hline & miniplates and elastics & 12 & -7.53 & 2.32 & 2 & 0.01 & -0.10 & 0.10 & 1.00000 \\
\hline & Control & 12 & 110.23 & 4.74 & & & & & \\
\hline U1/FP & miniplates and elastics & 12 & 111.69 & 3.84 & -1.40 & 1.14 & -2.02 & 1.90 & 0.0915 \\
\hline & Control & 12 & 86.93 & 2.09 & & & & & \\
\hline LI/IVII & miniplates and elastics & 12 & 87.29 & 2.52 & -0.50 & 0.94 & -2.02 & 1.00 & 0.10004 \\
\hline & Control & 12 & 30.61 & 2.37 & & & & & \\
\hline Sn-GoGn & miniplates and elastics & 12 & 32.78 & 3.24 & $-2.1 /$ & 0.80 & -1.83 & 1.50 & $0.83 / / 3$ \\
\hline
\end{tabular}


TABLE (4) Descriptive statistics for T2-T1 mean changes and comparison between the two study groups

\begin{tabular}{|c|c|c|c|c|c|}
\hline \multirow{2}{*}{ Parameter } & \multicolumn{2}{|c|}{ Group A (Miniplates) } & \multicolumn{2}{|c|}{ Group B (Control) } & \multirow{2}{*}{$P$ value } \\
\hline & Mean & $\begin{array}{l}\text { Standard } \\
\text { deviation }\end{array}$ & Mean & $\begin{array}{l}\text { Standard } \\
\text { deviation }\end{array}$ & \\
\hline $\mathrm{SNA}^{\circ}$ & 3.50 & 0.68 & 0.44 & 0.18 & $<0.001 * *$ \\
\hline $\mathrm{SNB}^{\circ}$ & -0.56 & 0.57 & 0.76 & 1.06 & $<0.01 *$ \\
\hline $\mathrm{ANB}^{\circ}$ & 4.06 & 0.95 & -0.32 & 0.98 & $<0.001 * *$ \\
\hline Witts (mm) & 4.91 & 1.76 & 0.29 & 0.11 & $<0.001 * *$ \\
\hline A-Nperp (mm) & 4.04 & 1.20 & -0.73 & 0.6 & $<0.001 * *$ \\
\hline Pog-Nperp(mm) & -1.85 & 1.36 & 1.59 & 0.47 & $<0.001 * *$ \\
\hline $\mathrm{U} 1 / \mathrm{PP}^{\circ}$ & 0.21 & 0.77 & 0.42 & 0.33 & $\begin{array}{c}P>0.05 \\
N S\end{array}$ \\
\hline $\mathrm{L} 1 / \mathrm{MP}^{\circ}$ & 6.43 & 2.11 & -0.53 & 0.22 & $<0.001 * *$ \\
\hline $\mathrm{SN} / \mathrm{GoGn}{ }^{\circ}$ & 0.58 & 0.38 & 0.15 & 0.71 & $\begin{array}{c}P>0.05 \\
N S\end{array}$ \\
\hline
\end{tabular}

$P<0.05 *($ Significant $) \quad P<0.01 *($ Highly significant $)$

\section{$P>0.05$ (Nonsignificant)}

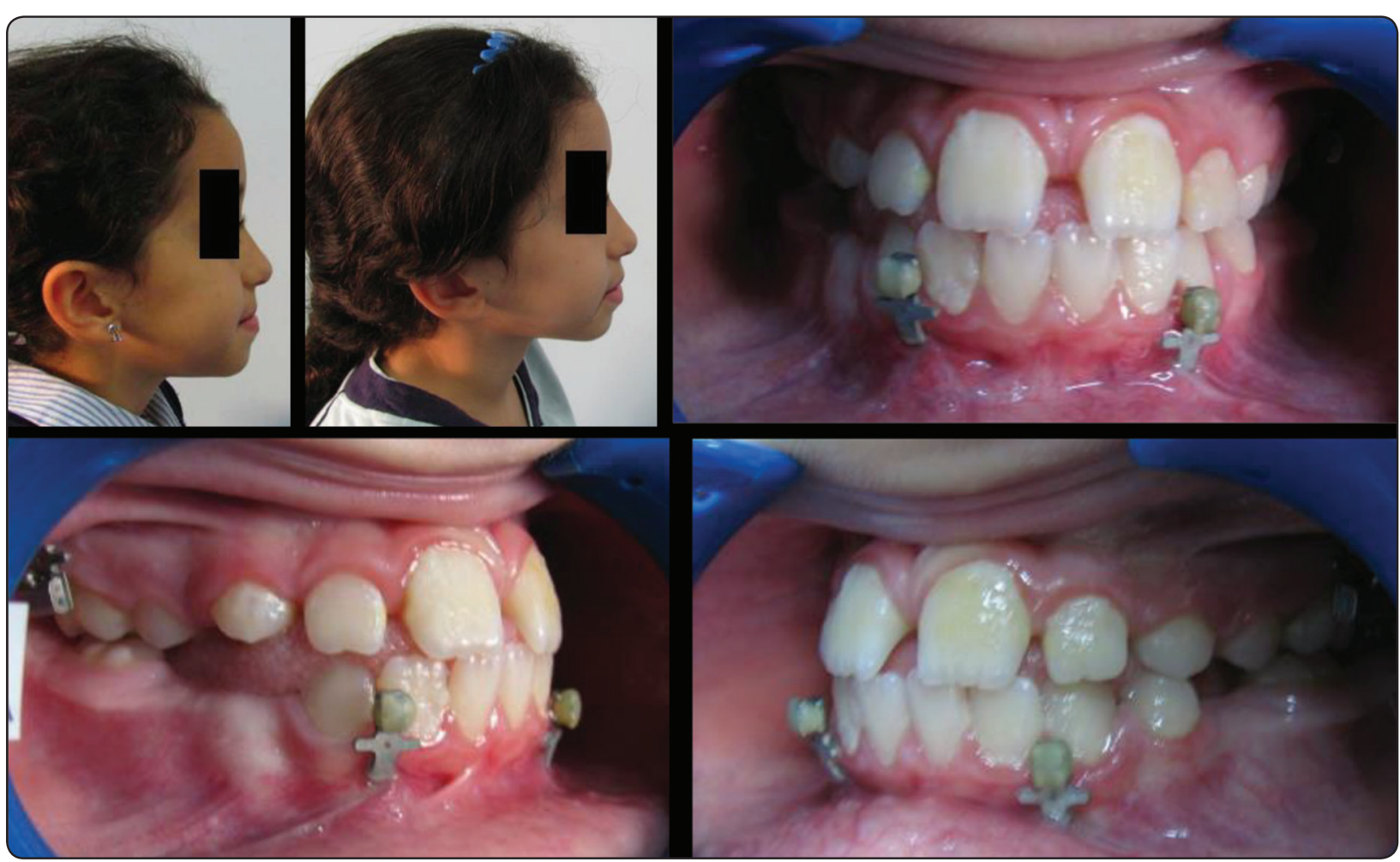

Fig. (3) Posttreatment photos of Skeletal Class III patient (Group A) 


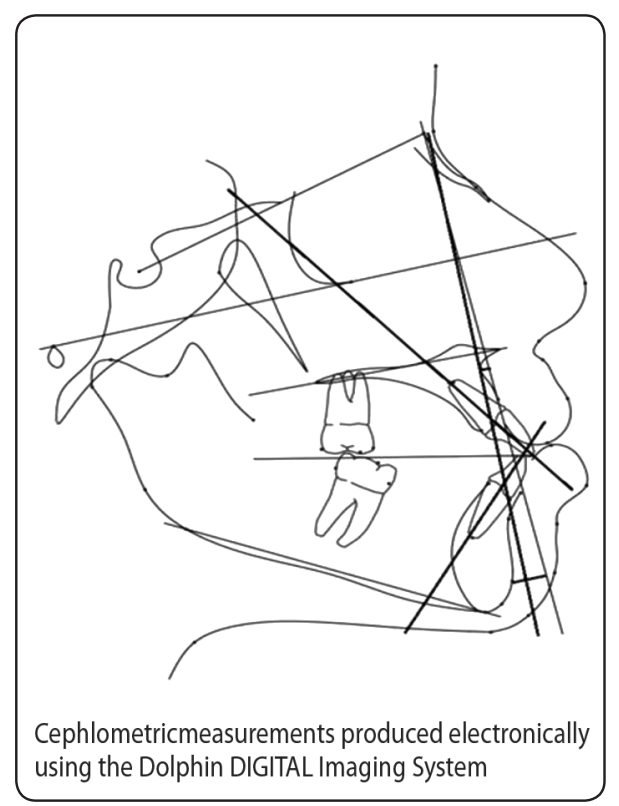

Fig. (4) Posttreatment lateral cephalometric tracing (Group A) at $\mathrm{T} 2$

\section{DISCUSSION}

When correcting skeletal Class III for growing individuals with maxillary insufficiency, the most favourable outcome is skeletal correction of the jaws without the undesirable side effects on dentition and facial height. To overcome the limitations of conventional facemask therapy due to forces being applied to teeth (Ishii et al, 1987; Battagel et al, 1993; Lim et al, 1995; Kapust et al, 1998; Kim et al., 1999 and Kama et al., 2006) bone anchored facemasks have been introduced for maxillary protraction with reports of more than $6 \mathrm{~mm}$ of maxillary advancement (Kircelli et al, 2006) as well as reductions in the anticlockwise rotation of the maxilla. Yet the side effects from dentoalveolar movements could not be totally overcome (Takada et al, 1993). Furthermore, problems with patient cooperation make it a less appealing modality of treatment (Singer et al, 2000; Hong et al, 2005; Kircelli et al, 2006 and EINagar et al, 2016).

A number of studies previously compared between miniplate anchored facemasks and other treatment modalities such as Sar et al, 2011 who compared between the skeletal and dental effects of 2 mechanisms for maxillary protraction where they found that facemask anchored to miniplates yielded better results in certain criteria than Class III elastics placed between a bonded maxillary appliance and mandibular miniplates. In the facemask group, there was less antoclockwise maxillary rotation which resulted in reduced clockwise rotation of the mandible. Therefore facemask anchored to maxillary miniplates was recommended in Skeletal Class III high angle patients. The proclination of the upper incisors was minimal. This is in contrast to conventional facemask treatment where there is significant increase in mandibular plane angle due to dentoalveolar molar extrusion and maxillary counterclockwise rotation (Takada et al, 1993). However, in the study of Sar et al, 2014 the control of lower incisor retroclination could not be achieved in the miniplate anchored facemask group. Therefore this treatment modality is not without its disadvantages. Class III elastics anchored to miniplates resulted in more maxillary advancement $(3.82 \mathrm{~mm})$ and lower incisor proclination instead of further retroclination.

Miniplates attached to the infrazygomatic crest of the maxilla and the symphysis of the mandible were implemented in this study as treatment of choice to evaluate and compare the effects of this type of anchorage on skeletal class III orthopedic correction compared to effects from normal growth changes without involving any dentition in the anchorage setup. A control group was included in the study to differentiate treatment changes from growth changes.

The mean age of the sample was 10.2 years with patients in the late mixed or early permanent dentition stage. This is an optimum age for implementation of the miniplates due to an improved quality of bone which results in better stability (De Clerck et al, 2009). Furthermore, it was important to wait for the lower permanent canines to erupt to avoid injury of its tooth bud during placement of the symphyseal miniplates. Others have also employed a similar 
age range in their studies (Nguyen et al, 2011 and Heymann et al, 2010). The choice of the infrazygomatic crest for placement of the miniplates was mainly to avoid damage to the underlying developing tooth buds of the permanent teeth.

The procedure for placement of the miniplates in the mandibular symphysis is quite invasive compared to skeletally anchored facemasks, as it requires an additional surgical operation at higher cost in the mandibular symphysis for placement of the miniplates. However, it was justified since the intraoral elastics are believed to be better tolerated by the patients as well as being inconspicious unlike the facemask (EINagar et al, 2016). The amount of force used with the Class III elastics in this study (200 grams) was significantly lower than the 600 grams of force required with the reverse pull headgear (Gallagher et al, 1998 and PangrazioKulbersh et al, 1998). Additionally, the lighter force permits constant forces up to 24 hour per day instead of the interrupted forces provided by facemask for a maximum of 14 hours/day.

The choice of the zygomatic buttress region in the maxilla for placement of the maxillary miniplates was justified as it is an area far from the permanent teeth buds present inside the bone (EINaggar et al, 2016). The only drawback with the usage of mandibular symphyseal miniplates was that in order to be able to fix the miniplate with screws, the lower permanent canine must have erupted. This means that treatment should be delayed till at least 9 years old to ensure eruption of the mandibular permanent canine. Otherwise, if earlier intervention is desired especially in Class III cases then it is advisable to modify the design of the miniplates by using an L-shaped type that can be anchored at the lower border of the symphysis.

The results of this study indicate more skeletal than dental effects with this treatment modality. The improvement in the sagittal jaw relationship was mainly due to anterior movement of the maxilla by a mean value of $5.04 \mathrm{~mm}$. There were increases in both angle SNA and Witts appraisal with mean values of $3.50^{\circ}$ and $4.91 \mathrm{~mm}$ respectively. This is in line with the study by Cevidanes et al, 2010 which concluded that bone-anchored maxillary protraction resulted in $2.3-3 \mathrm{~mm}$ more forward movement of the maxilla compared to facemask or rapid palatal expansion. Others (De Clerck et al, 2009; De Clerck et al, 2010 \& Heymann et al, 2010) reported 5.2 $\mathrm{mm}, 4 \mathrm{~mm}$ and $4.7 \mathrm{~mm}$ of advancement of the maxilla respectively due to pure bone-borne orthopedic forces between the upper and lower jaws using Class III elastics. This is due to the point of orthopedic force application being close to the center of resistance of the maxilla at the locations of the maxillary sutures which results in bodily anterior maxillary displacemet without rotation. The center of resistance of the maxilla is located between the root tips of the maxillary premolars (Hirato, 1984 and Tanne et al, 1988), whereas Miki, 1979 reported it to be between the roots of maxillary premolars in an anteroposterior plane, while in the vertical plane it is located between the orbit and distal root apex of maxillary first molars.

Regarding mandibular effects, there was slight reduction in the values of angle SNB and Pog-Naperp which reflects the restraining effects of Class III elastics on further mandibular growth with slight backward mandibular movement with mean values of $\left(.-0.56^{\circ}\right)$ and $(-2.23 \mathrm{~mm})$ respectively. Moreover there was no change in mandibular plane inclination. As for dental effects, there were no changes in upper incisors proclination or retroclination while mild proclination was seen in the mandibular incisors with an average of $6.43^{\circ}$. Similar results were observed by De clerck et al, 2009; De Clerck et al, 2010 and Heymann et al, 2010 who reported a decrease in angle ANB and improvement of at least $2 \mathrm{~mm}$ in the sagittal position of points B and pogonion. This all reflected a posterior relocation of the mandible. On the other hand, the explanation behind the lower incisor proclination in our study and 
theirs could be a change in soft tissue equilibrium due to increased tongue pressure on the lower incisors after correction of the anterior crossbite. Upper teeth in crossbite acted as a barrier for the lower teeth against any tongue pressure. This finding is contrary to the previous studies of skeletal class III correction which always reported mandibular incisor retroclination due to the use of conventional facemask therapy (De Toffol et al, 2008). The upper teeth did not procline due to pressure exerted on them from the upper lip.

Our results are also aligned with those of Nguyen et al, 2011 in their CBCT study where they stated that the maxilla moved forward by a mean value of $3.7 \mathrm{~mm}$ compared to only $2.3-3 \mathrm{~mm}$ from facemask and rapid palatal expansion. There was hardly any dental compensation in their results.

Coscia et al, 2012 underwent slight modification of the Class III elastics protocol by using a mandibular acrylic resin plate with hooks. However they attained orthopedic results similar to ours. The advantage of their technique was that they were able to start orthopedic correction regardless of the stage of lower canine eruption.

Lastly when (EINagar et al, 2016) performed a comparative study between miniplates anchored facemask and miniplates anchored Class III elastics, better results and control of skeletal and dental features were achieved by Class III elastics. More forward movement of the maxilla was noted in the Class III elastics group $(5.81 \mathrm{~mm})$ compared to the facemask group (4.87 mm). Moreover Class III elastics group provided better control of palatal plane rotation, lower incisor angulation and mandibular plane inclination. Further mandibular growth was impeded due to the restraining effect of Class III elastics. There was a mild reduction in mandibular plane angle but it was not statistically significant. This could be due to modifications in the ramal and condylar growth mechanisms as a result of Class III elastics forces (De Clerck et al, 2010 and
EINaggar et al, 2016). Another explanation is that this takes place due to reshaping of the mandible which depletes excessive growth of the mandible relatively to the maxilla (Tollaro et al, 2006).

When compared to controls, the results of this study were the opposite of the sagittal skeletal discrepancy associated with the untreated Class III patients (Guyer et al, 1986; Takada et al., 1993; Kapust et al., 1998 and Alexander et al., 2009) where the mandible continues to grow but the maxillary SNA stays the same and angle ANB decreases.

\section{CONCLUSIONS}

1. Bone anchored intermaxillary Class III elastics provide orthopedic correction of skeletal Class III malocclusion with maxillary deficiency with minimal dentoalveolar changes of the maxillary incisors. Only lower incisor proclination was evident.

2. No maxillary or mandibular skeletal rotational changes were evident.

\section{REFERENCES}

- Alexander AE, McNamara Jr JA, Franchi L, Baccetti T. Semilongitudinal cephalo- metric study of craniofacial growth in untreated Class III malocclusion. Am J Orthod Dentofacial Orthop 2009 Jun; 135(6):700.e1-14; discussion 700-1.

- Baccetti T, Franchi L, McNamara JA Jr. The cervical vertebral maturation (CVM) method for the assessment of optimal treatment timing in dentofacial orthopedics. Semin Orthod. 11 2005, p.119-129.

- Baccetti T, McGill JS, Franchi L, McNamara JA Jr, Tollaro I. Skeletal effects of early treatment of Class III malocclusion with maxillary expansion and face-mask therapy. Am J Orthod Dentofacial Orthop 1998; 113: 333-43.

- Battagel JM. The aetiological factors in Class III malocclusion. Eur J Orthod 1993;15:347-70.

- Cevidanes L, Baccetti T, Franchi L, McNamara JA Jr, De Clerck H. Comparison of two protocols for maxillary protraction: bone anchors versus face mask with rapid maxillary expansion. Angle Orthod 2010;80:799-806. 
- $\quad$ Chong YH, Ive JC, Artun J. Changes following the use of protraction headgear for early correction of class III malocclusion. Angle Orthod 1996; 66 : 351-362.

- $\quad$ Chung KR, Kim YS, Linton JL, Lee YJ. The miniplate with tube for skeletal anchorage. J Clin Orthod 2002;36: 407- 412 .

- Cornelis MA, Scheffler NR, De Clerck HJ, Tulloch JF, Behets CN: Systematic review of the experimental use of temporary skeletal anchorage devices in orthodontics. Am J Orthod Dentofacial Orthop 131(Suppl. 4): 2007; S52-S58

- Coscia G, Addabbo F, Peluso V, D’Ambrosio E . Use of intermaxillary forces in early treatment of maxillary deficient Class III patients: Results of a case series. J Craniomaxillofac Surg. 2012 Dec;40(8):e350-4.

- De Clerck H, Cevidanes L, Baccetti T. Dentofacial effects of bone-anchored maxillary protraction: a controlled study on consecutively treated Class III patients. Am J Orthod Dentofacial Orthop 2010;138:577-81.

- De Clerck HJ, Cornelis MA, Cevidanes LH, Heymann GC, Tulloch CJ. Orthopaedic traction of the maxilla with miniplates: a new perspective for treatment of midface deficiency. J Oral Maxillofac Surg 2009; 67: 2123-2129.

- De Toffol, Pavoni C, Baccetti T, Franchi L, Cozza P. Orthopedic treatment outcomes in Class III malocclusion. A systematic review. Angle Orthod 2008;78:561-73.

- $\quad$ Ellis E, McNamara Jr JA. Components of adult Class III malocclusion. J Oral Maxillofac Surg 1984; 42: 295-305.

- Elnagar MH, Elshourbagy E, Ghobashy S, Khedr M, Evans CA. Comparative evaluation of 2 skeletally anchored maxillary protraction protocols. Am J Orthod Dentofacial Orthop. 2016; 150: 751-762.

- Enacar A, Giray B, Pehlivanoglu M, Iplikcioglu H. Facemask therapy with rigid facemask treatment: a case report. Angle Orthod. 2005; 75: 453-460.

- Gallagher RW, Miranda F, Buschang PH. Maxillary protraction: treatment and posttreatment effects. Am J Orthod Dentofacial Orthop 1998; 113: 612-619.

- Guyer EC, Ellis 3rd EE, McNamara Jr JA, Behrents RG. Components of class III malocclusion in juveniles and adolescnets. Angle Orthod 1986; 56:7-30.

- Heymann GC, Cevidanes L, Cornelis M, De Clerck HJ, Tulloch JF. Three-dimensional analysis of maxillary protraction with intermaxillary elastics to miniplates. Am J Orthod Dentofacial Orthop 2010;137: 274-284

- Hirato R. An experimental study of the center of resistance of nasomaxillary complex: 2-dimensional analysis on the coronal plane in the dry skull. J Tokyo Dent Coll 1984;84:1225-62.

- Hong H, Ngan P, Han G, Qi LG, Wei SH. Use of onplants as stable anchorage for facemask treatment: a case report. Angle Orthod 2005; 75:453-460.

- Ishii H, Morita S, Takeuchi Y, Nakamura S. Treatment effect of combined maxillary protraction and chincap appliance in severe skeletal Class III cases. Am J Orthod Dentofacial Orthop 1987; 92:304-12.

- $\quad$ Kama JD, Ozer T, Baran S. Orthodontic and orthopaedic changes associated with treatment in subjects with Class III malocclusion. Eur J Orthod 2006; 28: 496-502.

- Kapust AJ, Sinclair PM, Turley PK. Cephalometric effects of face mask/expansion therapy in Class III children: a comparison of three age groups. Am J Orthod Dentofacial Orthop 1998;113: 204-212.

- $\quad$ Kaya D, Kocadereli I, Kan B, Tasar F. Effects of facemask treatment anchored with miniplates after alternate rapid maxillary expansions and constrictions: a pilot study. Angle Orthod 2011;81:639-46.

- $\quad$ Kim JH, Viana MA, Graber TM, Omerza FF, BeGole EA. The effectiveness of protraction face mask therapy: a meta analysis. Am J Orthod Dentofacial Orthop 1999; 115: 675-685

- $\quad$ Kircelli BH, Pektas ZO, Uckan S. Orthopaedic protraction with skeletal anchorage in a patient with maxillary hypoplasia and hypodontia. Angle Orthod 2006; 76: 156-163.

- $\quad$ Kokich VG, Shapiro PA, Oswald R, Koskinen-Moffett L, Clarren SK. Ankylosed teeth as abutments for maxillary protraction: a case report. Am J Orthod 1985; 88: 303-307.

- $\quad$ Lim JK, Park YC. A study on profile change of skeletal Class III malocclusion patients after wearing protraction headgear. Korean J Orthod 1995;25:375-401.

- Miki M. An experimental research on the directional control of the nasomaxillary complex by means of external force-two-dimensional analyses on the sagittal plane of the craniofacial skeleton. J Tokyo Dent Coll 1979; 79: 1563-97. 
- Nguyen T, Cevidanes L, Cornelis MA, Heymann G, de Paula LK, De Clerck H. Three-dimensional assessment of maxillary changes associated with bone anchored maxillary protraction. Am J Orthod Dentofacial Orthop 2011; 140:790-8.

- $\quad$ Pangrazio-Kulbersh V, Berger J, Kersten G. Effects of protraction mechanics on the midface. Am J Orthod Dentofacial Orthop 1998; 114: 484-491.

- Sar C, Arman-Özçırpıcı A, Uçkan S, Yazıcı AC. Comparative evaluation of maxillary protraction with or without skeletal anchorage. Am J Orthod Dentofacial Orthop. $2011 ; 139(5): 636-49$.

- Şar C, Şahinoğlu Z, Özçırpıcı AA and Uçkan S. Dentofacial effects of skeletal anchored treatment modalities for the correction of maxillary retrognathia. Am J Orthod Dentofacial Orthop 2014; 145:41-54.

- $\quad$ Singer SL, Henry PJ, Rosenberg I. Osseointegrated implants as an adjunct to face- mask therapy: a case report. Angle Orthod 2000; 70: 253-262.

- Takada K, Petdachai S, Sakuda M. Changes in dentofacial morphology in skeletal Class III children treated by a modified maxillary protraction headgear and a chin cup: a longitudinal cephalometric appraisal. Eur J Orthod 1993; $15: 211-221$.

- $\quad$ Tanne K, Miyasaka J, Yamagata Y, Sachdeva R, Twutsumi S, Sakuda M. Three dimensional model of the human craniofacial skeleton: method and preliminary results using finite elements analysis. J Biomed Eng 1988;10:246-52.

- Tollaro I, Baccetti T, Franchi L. Craniofacial changes induced by early functional treatment of Class III malocclusion Am J Orthod Dentofacial Orthop. treatment in subjects with Class III malocclusion. Eur J Orthod 2006; 28: 496-502.

- $\quad$ Turley PK. Managing the developing Class III malocclusion with palatal expansion and facemask therapy. Am J Orthod Dentofacial Orthop 2002; 122: 349-352.

- Williams MD, Sarver DM, Sadowsky PL, Bradley E. Combined rapid maxillary expansion and protraction facemask in the treatment of Class III malocclusions in growing children: a prospective long- term study. Semin Orthod 1997;3:265-74. 